\title{
Falling into the Surface (toward a materiality of affect) ${ }^{1}$
}

\author{
Pia Ednie-Brown
}

"Motionless on the surface, in its very depth it lives and vibrates."

( $f$ constant concern to the discipline of architecture is the effectual nature of its processes of production. As a practice, architecture struggles with a coordination of the extremely variegated and complex field of forces that come to play in the creation of a building. Ultimately, the imperative of the performance is to sustain its effective consequentiality. The security of its stature and relevance has relied on a maintenance of belief in the significance and responsibility of form. Architectural history presents a catalogue of renovations and additions to the structure of its rhetoric of authority. The shifts of persuasion driving the processes of history's architectural undertakings have pivoted on an import of form.

Lately, the "virtual" has risen to the surface of architectural discourse through a reverberative tremor of prevailing cultural desires. The term "virtual" is often used as a convenient and attractive packaging aimed at consumptive desires for increased mobility while, paradoxically, keeping "mobility" contained and vacuum packed. In a climate of cultural production that invests explicit movement with sovereign value, the insistent stasis of buildings has been absurdly claimed to signal an imminent obsolescence of architecture. The foundations of authority upon which architecture has curated its catalogue have begun to crack. The challenge of how architectural design processes could be re-articulated to address active engagements with the virtual has become a source of experimentation. Reactionary efforts toward revaluation have at times evoked the Emperor in his (virtual) new clothes: sensational, but forgetting actual sensation. The opportunities presented to contemporary architecture are not to be found in a subservience to illusions of this kind. Rather, they lie in the manner with which the operations of architectural practices realign their affiliation with the concrete actuality of buildings as an engagement with the virtual.

Brian Massumi, in his paper "Sensing the Virtual, Building the Insensible," calls up "radical" or "superior" empiricism as the answer to his question: "what philosophy can or might enter into a symbiosis with architectures engaging with the virtual ...?"3 He goes on to suggest that "for architecture, the effect of such a symbiosis is a willingness to bring into even more pronounced expression its processual dimensions." ${ }^{\prime 4}$ Design and construction processes are always insinuated in the building itself. As that which steers their formation, they are never not expressed-even if unconsciously. It is the "willingness" and the "even more pronounced" of Massumi's suggestion that become the imperatives. This paper attempts to articulate modalities through which these imperatives may be addressed.

The manner in which radical empiricism expresses the virtual within lived experience, as always insinuated in actual events, imbricates it with the actuality and solidity of buildings. This holds great potential for the development of architectural practices, in that the conceits 
produced by dichotomous logic can be productively redressed. Where there can be no actuality without the virtual, stasis no longer points to a death (of architecture) but to an invigoration of the zone of potential that plays around the concrete. This impacts directly upon the limits and dimensions of processuality, as it involves a shift in the arrangements with which the modalities of practice can engage with the virtual. Contrary to a placement of events according to a division between supposedly exclusive terms — form and social praxis, for example — there is a more subtle relation of intertwinement, which, in as much as it still presents a division, has itself been realigned. As Philip Goodchild writes: "The fundamental division is no longer that between the subjective and the objective, the mental and the material, artifice and nature, but between spontaneity and receptivity: the power to affect and the power to be affected." This shift of attention invigorates the potentiality of the relations themselves.

Within these folded realignments, Massumi's suggestion can be seen to have simultaneous relevance to both processes of design and experiential processes involved in the "completed" building itself. This fundamental issue of radical empiricism challenges architectural discourse, which has a blithe tendency to regard anything after the closure of construction and prior to an appearance in the pages of an historical text to be outside the interest and authority of the discipline. This gap in disciplinary attention has arisen in tandem with the hold that subjectivity has maintained on questions of experience. In humanist models of subjectivity, the subject, the perceiver, holds the balance of power (to affect and be affected). The building (or object) falls into a realm of unspeakable action in that it cannot be contained by authoritative moulds. Radical empiricism invites an effort to both acknowledge and realign these otherwise silent, but nevertheless inscriptive affects. Significantly, the restructuring of relations with which this effort is undertaken is set up such that acknowledgments of the virtual do not fall back into the insistent banality of disciplinary authority. The task is to release life (the virtual) wherever it may be trapped.

Radical empiricism calls up this challenge through a vastly expanded notion of subjectivity that invites architecture to stretch out and test its processual limits. Félix Guattari set out the extended limits of this refigured subjectivity in his final book, Chaosmosis: An EthicoAesthetic Paradigm, in which he writes: "How are the new fields of the possible going to be fitted out? How are sounds and forms going to be arranged so that the subjectivity adjacent to them remains in movement, and really alive?"6 Embedded within this passage is a radical (empirical) twist. The problem is not subjective uncertainty but how subjectivity is kept alive; how significance can be released from the classical moulds of objectivity. Objectivity is merely fixed subjectivity: the subjective forced still. The life of subjectivity is not simply in the shifts of an interpretative field but the operations of a set of engagements, a "machinic assemblage." Here the subjective is not "originated" in an individual rather it is produced through the transitory assemblages of a vast array of impersonal forces.

These assemblages crystallize or precipitate through a twist onto a surface that expresses the textures of perception. In turning to touch, to make sense of this tactility, these emergent, textural signs are contracted into tools of action. The act of contraction divides this information into distinct modalities whereupon perception emerges and reconverges as geometrical, reasonable forms of appearance. Subjectivity moves about these contractions and dilations of the processes of surfacing. Designing arrangements that may actively keep subjectivity alive, falls back upon setting out the conditions or parameters of processes that are themselves open and mobile. 


\section{Forming Habits}

Architectural practice has a tendency to establish the visualization of form as the primary condition enabling processes of design. Form, as an exercise in itself, untied to the specificities of durational presence (matter), is linked to the status of geometry as an idealized phenomenon. Geometrical laws appear as universal truths cut free from temporality and the affective dimensions of historicity. Ideally, an equilateral triangle was the same for Pythagoras as it is for us today. As an Idea, geometry arrives as an already-made, an unchanging set of truths that simply exist, apparently prior to and separate from perception. In the work of French philosopher, Henri Bergson, there is an effort to turn back upon the conditions within which geometry emerges. Geometry and form are thereby rendered as contingent, undermining their claim to universality. As Bergson writes: "the universe is not made, but is being made continually." ${ }^{\prime \prime}$

Perception of space and form is defined by that which Bergson calls a "virtual geometry." In Creative Evolution he explains: "You cannot present this space to yourself without introducing, in the same act, a virtual geometry which will, of itself, degrade itself into logic, for, space cannot be given without positing also logic and geometry, which are along the course of the movement of which pure spatial intuition is the goal." ${ }^{8}$ Form, arrived at through logical interpolations upon virtual geometries, becomes a habit secreted from memory: empirical information accumulates in mnemonic refrains and inscribes itself through patterns of perception. Pure form, on the other hand, as an idealized, static geometry, violates memory through a suppression of its power to affect; it is a ready-made set of laws of dry and seemingly autonomous consistency. These laws are so consistent that they insist on being (true) and defy the transformative impulse of becoming. Bergson suggests that consciousness must "detach itself from the already-made and attach itself to the beingmade" in order for it to engage with the principles of its emergence. ${ }^{9}$ Already-made laws tend to restrain the perceived from flowing out of strictly delimited moulds, and train it to abrogate the shifts that rustle across the surface of perception. They maintain an impeccable garden in which new life is already tame and unplanned emergence is outlawed.

When architects design primarily through the manipulation of form they will tend to assume the already-made of form itself. Particular forms will emerge, but form itself loses potential dimensions of mobility in the process. This is no less the case in the movements of morphing computer animations than in orthogonal extrusions of floor plans. How might architectural practice turn back upon and attach itself to the being-made of form? How can form affect and be affected by movements not already contained within the parameters of a form driven process? This requires a departure from such processual habits, venturing instead into a sensitized field.

\section{Becoming Sensitive}

The operations of this sensitized field can be usefully illustrated with Massumi's account of warm water:

If heat is increased at a certain rate, a threshold is reached at which order spontaneously arises out of chaos. The liquid differentiates. Certain regions turn in on themselves, "nucleate" form fluid boundaries. Whirlpools form: convection 
currents. These vortices appear because the liquid is under another constraint besides the command to regain equilibrium through thermodiffusion. That second constraint is gravity ... In the process, the liquid became "sensitive." The effect of gravity on a liquid at rest is normally negligible, but in its agitated state, the liquid suddenly "perceived" it and was transformed. ${ }^{10}$

Here, the process of becoming sensitive involves the awareness or perception of an otherwise relatively latent presence. The vortices swirl the liquid into a moment of intensive order, such that the entire body of water becomes highly coordinated and "any chance disturbance that might occur in one area will immediately be 'felt' everywhere."11 A set of relations is at once articulated, and this is what the ldea of pure form seeks to obliterate: namely, the conditions of its emergence.

Think of any moment in which instability arises. Say, for instance, you teeter and fallor almost fall. The experience is one in which the sensation of gravity lurches forward as an amplified presence. This sensation can be completely overwhelming - as if an invisible hand has thrown you. Commonsense falls apart as the senses fall together into the realm of sensation. You become integrated and dispersed across a singularly coordinated gesture. In this example, the limits of the subject become uncertain. Subjectivity becomes sensitive.

Typically, gravitation is the habitually ensconced forgotten of the upright world. Deeply implicated in the formation of all our habits, gravitation is a critical dimension in the processes and organization of perception. According to Buckminster Fuller, "Gravity is the inside outness of energy-as-matter: the integrity of Universe."12 It is the vital pulse. Things fall, no doubt about it, but the fall is one into potentiality as much as a falling down to the ground. A fall into the surface is a leap of potentiality. It entails both the rise and fall of affect. A willingness to fall is an openness to the power to affect and be affected. The categories of the animate (life) and the inanimate (matter) necessarily fall into one another. As Bergson writes:

The vision we have of the material world is that of a weight which falls: no image drawn from matter, properly so called, will ever give us the idea of the weight rising. But this conclusion will come home to us with greater force if we press nearer to the concrete reality, and if we consider, no longer only matter in general, but, within this matter, living bodies. ${ }^{13}$

The passing of "living bodies" through matter can be as simple as heat through water. "Living" is not simply an attribute of organisms, for it subsists in all matter. Living becomes a virtual reality. The life that passes is the reality of change. Both water and heat, in falling into one another, are mutually affected. The event of becoming sensitive is an intensification in the power of change. Something extra is perceived. This extra dimension was always there, but not yet explicitly active, not yet becoming explicit, in the changes occurring in the system.

Design processes that become sensitive have the potential to make far more explicit processual dimensions. Where process itself is open to the perception of otherwise implicit dimensions, it becomes capable of "even more pronounced expression its processual dimensions." 


\section{Hypersurfacing}

Rearticulating classical divisions of architectural design is at the basis of Stephen Perrella's Hypersurface theory. As he writes: "Hypersurfaces are an interweaving and subsequent unlocking of culturally instituted dualities."14 In attempting to situate the development of this theory in relation to the imperatives investigated here, the hypersurface can be twisted into a roaming verb so as to encounter the potentiality of its actions. More specifically, it becomes a useful expression of the becoming explicit of extra-dimensionality.

Surface, in common parlance, is generally understood as the exterior boundary of things, the outer skin of any object. In this sense, surfaces are actual, material, textural entities that are the most directly perceived and felt aspects of the world. They are that which we directly encounter. The surface is also taken to be something that conceals: "it was not what it appeared to be on the surface." When things surface, they become evident or apparent; they appear out of a previously concealed existence or latency. Surfacing is an action of becoming explicit, of becoming experientially apparent in a movement from virtuality to actuality — of becoming expressed across the limits of perception. Surfacing is the process of becoming perceptible and actual.

To be hyper is to be overexcited, super-stimulated, excessive, on edge. This state of intensity is a mode of over-being: an excess of being in that the processes of becoming exceed constraints to existence. Things foam at the edges.

The "hyper," when conjoined with "surface," turns up the volume on emergence: it is a becoming more than simply explicit, an "even more pronounced expression [of] its processual dimensions." Between the explicit act and the myriad of potential acts, consciousness ${ }^{15}$ finds its emanative expression. Hypersurfacing unleashes the surface into bearing witness to an even more pronounced expression of the conditions of emergence.

Hypersurfacing is an act of falling into the surface.

\section{Fallibility: Tending Toward a Materiality of Affect}

In a moment of intensive rupture, such as falling, the body twists open into an extradimensionality, attaining an extensivity than renders both the "self" and the object as highly contingent. A release from absolute valuations of self and object-hood is implicit in the imperative of willingness, as Massumi suggests. Engagements with the virtual are amplified with a porosity across which an active folding out and infolding can become operational. Through a willingness to fall open, the play of the dice is admitted into the dimensions of processuality. ${ }^{16}$ Chance events can enact their regenerative impulse. The release from the primacy of the human subject, fundamental to the efforts of radical empiricism, enables the potentiality of an event as an arrangement of "connectibilty." As Massumi writes, "What is virtual is the connectibility: potential (the reality of change). It cannot be overemphasised that the virtual is less the connection than its -ibility."17 Similarly it must be emphasized that to "fall into the surface" is not exclusively a falling down, it is an opening out into the readiness of change, into a sensitivity to potentiality. This is leading to the articulation of a tendency that I will call fallibility; an admittance of errant ways. Fallibility becomes an imperative of "willingness." 
A useful model for the arrangement of processes that address this imperative can be found in the wind-drawing machine of artist Cameron Robbins. This machine performs through mechanisms driven by both the speed and direction of the air. Working within certain tendencies and patterns, all the drawings produced by this quite simple machine express the specificity of their duration. Each has its own enigmatic quality. The actions of the process or mechanism are such that the ink tends to be marked out more or less within a circular outer limit. This is more or less the case because the machine is, in itself, sensitive enough for chance to cut in: for the intensities of forces to throw the pen into paroxysms of leaping that extend beyond the provisional limits of its less intensified paths; for rain to splatter and spread the ink; for things to go "wrong" such that the (even more) unexpected will emerge.

No attempt is made to control the environment in which the act of production takes place. Rather than enveloping the process with an authorial container, the processual engagements are granted a spontaneous dimensionality of life. That which is designed is the mechanisms of perception: the in-built receptivity that arranges and renders explicit the forces within which perception endures. The process of production is open and sensitive to the specificities and complexities of its duration. That which is made explicit is the interplay of affects in the lived experience of the mechanism "out for a walk."18

The prevailing trend in architectural practice is to establish a processual relationship in which intended or (at least partly) preconceived formal outcomes direct the paths of production. Within the wind-drawing process, this relationship becomes inverted. The process of production, within mutable limits, governs the formal outcome. In turn, form itself takes on an expanded ontology. As an expression of affects at play in the process of formation, form takes on its own materiality. Materiality is no longer subservient to the desires of a designated form.

This more expansive, durational notion of form can thereby be understood as the materiality of affect. As much as this materiality is of insistent virtuality, it is implicit to the actual. Form gathers an extra-dimension of expression. The vast array of impersonal forces productive of subjectivity actualizes into a consistency expressive of manifold duration. Rather than form being enmeshed with humanist models of perception, form is gathered through the engagement of potentiality.

What I am finally able to suggest is that design experimentations aiming for engagements with the virtual might depart from their current impasse of nostalgia should they turn their processual arrangements away from form and the movement of form, and instead toward processes that are themselves open and mobile. This does not mean designing morphic architecture. Rather, it involves a willingness to break out of self-perpetuating habits. Through modes of fallibility, experimentations can expand their processual dimensions and propel them into even more pronounced expressions. What then may emerge are buildings that emanate in a materiality of affect.

\section{A Final Admission (A Falling Open)}

"Art does not reproduce the visible; rather, it makes visible."19 
A dimension of this paper is yet to be made explicit. Subsisting throughout this text is a particular event, of a certain extra-dimensional quality in itself, which took place in 1997. It is at once the connectibility of this paper and the fallibilty that underwrites it.

As part of a design studio I conducted at RMIT, Cameron Robbins accompanied my students and me on a trip to the southern most shoreline of mainland Australia. It was, perhaps needless to say, a site of wind-driven intensity. Shortly after arrival Cameron set the machine into action and we walked with the students around the cape. At one stage we reached a fence. In a clumsy attempt to climb over, I fell. In the moment of losing balance it unmistakably felt as if I was pushed ... as if a strong, invisible hand had loomed up from behind and thrown me. In falling I lost myself; any sense of "I" was dissolved in a far greater impulsion. My surroundings collapsed; exteriority became articulated only as an antinomy of stasis. Time stretched and dissolved into an expanded flight of perplexity. It wasn't until after hitting the ground that I managed to gather a clear comprehension of the event: I had fallen. Sitting up, I faced an audience of shocked faces, their anemic hue registering the gash in my blood spurting chin. My body had become the machine through which gravity made its extra mark. Releasing me from this cast of bloodshot eyes, Cameron and the students went back to the machine to see what had been produced. They discovered that part of the mechanism had been blown over in our absence. The drawing itself was somewhat unusual (the machine having been altered with the fall) and strangely resembled an eye. Musing on the apparent simultaneity of falls, Cameron titled it The Fall of Pia: an exfoliation off the scaly surface of authoritarian certainty. The coincidence of the falls and the uncanny appearance of the eye produced a palpable sense of some virtual form - a becoming explicit of a materiality of affect ... designed in a partnership perhaps with "Dionysus snickering at fate as he steals an extra turn."20

It would be easy to think of the falling in terms of genetically coded clumsiness. Instead, for reasons of an uncertain kind, I'm inclined to see it as a pure event of fallibility.

\section{References}

Bergson, Henri. Creative Evolution . Translated by Arthur Mitchell. New York: Dover Publications, 1998. 1991 .

Matter and Memory. Translated by Nancy Margaret Paul and W. Scott Palmer. New York: Zone Books,

Deleuze Gilles and Félix Guattari. Anti-Oedipus: Capitalism and Schizophrenia . Translated by Robert Hurley, Mark Seem, and Helen R. Lane. Minneapolis: University of Minnesota Press 1994.

Fuller, Buckminster. Synergetic: Explorations in the Geometry of Thinking . New York: MacMillan, 1979.

Goodchild, Philip. Deleuze and Guattari: An Introduction to the Politics of Desire . London: Sage Publications, 1996.

Guattari, Félix. Chaosmosis: An Ethico-Aesthetic Paradigm . Translated by Paul Bains and Julian Pefanis. Sydney: Power Institute, 1995.

Paul Klee. "Creative Credo." 1920. In The Inward Vision: Watercolours, Drawings and Writings by Paul Klee. Translated by Norbert Guterman. New York: Abrams, 1959.

Massumi, Brian. A User's Guide to Capitalism and Schizophrenia: Deviations from Deleuze and Guattari. Cambridge, Mass.: The MIT Press, 1992. 22-23.

."Sensing the Virtual, Building the Insensible." Architectural Design: Hypersurface Architecture 68.5/6 (1998):

Perrella, Stephen. "Hypersurface Theory: Architecture><Culture." Architectural Design: Hypersurface Architecture 68.5/6 (1998): 6-15. 


\section{Notes}

1. Due thanks and acknowledgment is extended to Ned Rossiter for his generous and invaluable contributions to this paper. Thanks must also be extended to Robyn Barnacle, Brent Allpress, Peter Morse, and Stephen Perrella.

2. Bergson, Matter and Memory, 204.

3. Massumi, "Sensing the Virtual," 22-23.

4. Ibid., 23.

5. Goodchild, Deleuze and Guattari, 27.

6. Guattari, Chaosmosis, 133

7. Bergson, Creative Evolution, 241.

8. Ibid., 212.

9. Ibid., 237.

10. Massumi, A User's Guide to Capitalism, 59-60.

11. Ibid., 61.

12. Fuller, Synergetics, 306.

13. Bergson, Creative Evolution, 245.

14. Perrella, "Hypersurface Theory," 7 .

15. As Bergson states: "Consciousness is the light that plays around the zone of possible actions or potential activity which surrounds the action really performed by the living being. It signifies hesitation or choice." Bergson, Creative Evolution, 144.

16. "Every moment in life is a step in a random walk. Uncannily familiar as the shore may seem, looking back reveals no Eden of interiority and self-similarity, no snowflake state to regain. Ahead lies nothing with the plane reliability of solid ground. You can never predict where the subatomic particle will appear, or what will flash across the synapse (the pure instantaneous event). Once thrown, however, the dice are destiny. God as a drunken gambler. Dionysus snickering at fate as he steals an extra turn." Massumi, A User's Guide to Capitalism, 23.

17. Massumi, "Sensing the Virtual, Building the Insensible,"23.

18. "A schizophrenic out for a walk is a better model than a neurotic lying on the analyst's couch. A breathe of fresh air, a relationship with the outside world." Deleuze and Guattari, Anti-Oedipus, 2.

19. Klee, "Creative Credo," 5.

20. See note 16 . 